\title{
Evaluation of Non-Neoplastic Pathology in Tumour Nephrectomy Specimens
}

\author{
Dr. Sana Fatima ${ }^{1 *}$, Dr. Annapoorna Sireesha ${ }^{2}$, Dr. Bhanupriya Kakarala ${ }^{3}$ \\ ${ }^{1}$ Assistant Professor, Bowring \& Lady Curzon Medical College, 1, Lady Curzon Rd, Shivaji Nagar, Bengaluru, Karnataka 560001, \\ India \\ ${ }^{2}$ Associate Professor, Osmania Medical College, 5-1-876, Turrebaz Khan Rd, Troop Bazaar, Koti, Hyderabad, Telangana 500095, \\ India \\ ${ }^{3}$ Consultant Pathologist, Medall Health Care, Vijayawada, Andhra Pradesh, India
}

\begin{tabular}{l|l}
\hline DOI: $10.36348 /$ sjpm.2021.v06i01.009 & | Received: 10.01 .2021 | Accepted: 22.01 .2021 | Published: 28.01 .2021 \\
*Corresponding author: Dr. Sana Fatima &
\end{tabular}

\section{Abstract}

Renal neoplasms are one of the most common cancers contributing to significant morbidity and mortality. In patients undergoing nephrectomy for renal neoplasm, the structural integrity and function of contralateral kidney assumes extreme importance. Non-neoplastic renal tissue accompanying the tumour provides an opportunity to recognize non neoplastic pathological changes and to identify patients at risk for progressive renal disease after nephrectomy. The purpose of this study is to evaluate the spectrum of non-neoplastic lesions in tumour nephrectomy specimens. We reviewed the hematoxylin and eosin stained slides of 100 tumour nephrectomy specimens with our emphasis on studying the non-neoplastic renal parenchyma. Our study revealed significant non-neoplastic lesions in 76 of the total 100 specimens evaluated with Diabetic Nephropathy being the most common (36\%). Identification of renal non-neoplastic pathology may lead to initiation of medical intervention and can facilitate early preventive and treatment measures ensuring better quality of life for the patient.

Keywords: Tumour nephrectomy, chronic kidney disease, renal cell carcinoma, diabetic nephropathy, chronic pyelonephritis.

Copyright (C) 2021 The Author(s): This is an open-access article distributed under the terms of the Creative Commons Attribution 4.0 International License (CC BY-NC 4.0) which permits unrestricted use, distribution, and reproduction in any medium for non-commercial use provided the original author and source are credited.

\section{INTRODUCTION}

Renal malignancies are one of the most common carcinomas diagnosed worldwide with an increase in incidence rate in recent years. The most frequent type of renal malignancy is Renal Cell Carcinoma (RCC), which accounts for approximately $85 \%$ of all renal malignancies [1]. The 5 year relative survival rate is $92 \%$ for localized tumours [2].

Renal cell carcinoma arises from the renal parenchyma, particularly from the cells of the nephron and can be further specified into histological subtypes. Clear cell RCC (70\%) which arises from the proximal convoluted tubule, is the most common histological subtype, followed by papillary carcinoma.

The most common risk factors for renal malignancies are cigarette smoking, obesity and hypertension. Acquired cystic kidney disease is also a significant risk factor, especially in patients undergoing dialysis. There is increasing evidence of a strong association of renal malignancy with alcohol consumption. Few analgesics and occupational exposure have been associated with an increased risk of renal cell carcinoma.

The recent years have witnessed rapid rise in the burden of various non-communicable diseases, which can adversely impact the kidney. India leads the world with largest number of diabetic cases; the number of people with diabetes in India is currently around 40.9 million, which is expected to rise to 69.9 million by 2025 [3]. The important diseases in this category include diabetes mellitus, hypertension, connective tissue disorders like Systemic Lupus Erythematosus, amyloidosis etc. Primary reasons for rise in noncommunicable diseases in India are nutrition and lifestyle changes. So it is not surprising that many patients with renal neoplasms may harbour co-existing non-neoplastic pathology. 
Pathological changes in non-neoplastic renal parenchyma of tumour nephrectomy specimens and the significance of these changes with regard to the outcome of contralateral kidney function has not assumed much importance in earlier studies. The functioning of contralateral kidney has utmost importance in the follow up of the patient. Nephrectomized patients are at an increased risk for postoperative decline in renal function potentially because of pre-existing renal parenchymal changes, secondary to age-related changes or comorbid medical conditions. The histopathological evaluation of tumour nephrectomy specimens has always been focused entirely on the renal mass with analysis of parameters like size, margin status, capsule or renal vein invasion. This focus has led to chronic kidney disease being overlooked during reporting. Therefore a thorough preoperative clinical assessment and histopathological study of the non-neoplastic portion of the resected tumour nephrectomy specimens may provide valuable diagnostic and prognostic information for appropriate management.

Diabetes is an established risk factor for developing RCC $[4,5]$ and is present in approximately $10 \%$ to $20 \%$ of RCC patients [6, 7]. Pathological features of Diabetic Nephropathy are seen in up to $20 \%$ of tumour nephrectomy specimens [8, 9]. Diabetic nephropathy demonstrates a constellation of histopathological changes affecting all four anatomic compartments of the kidney. Initially the glomeruli become enlarged. Diffuse thickening of both the tubular and glomerular basement membranes gradually develops. Diffuse mesangial matrix deposition is found and may be difficult to identify in the early stages. Additional features of Diabetic Nephropathy are hyalinosis or insudative lesions (fibrin caps and capsular drops) that represent localized collections of plasma proteins.

Arterionephrosclerosis (also called hypertensive nephropathy/nephrosclerosis) is another common finding in adult tumour nephrectomies. The pathological diagnosis of arterionephrosclerosis is based on a constellation of nonspecific histopatholgical features. The gross appearance of kidney shows granularity of the capsular surface, which corresponds to the light microscopic glomerular and tubulointerstitial scarring due to vascular injury. Additional light microscopic features include proliferative and fibrotic intimal thickening with narrowing of the arteries with replication of the internal elastic lamina. In the absence of an immune complexmediated injury, the combination of global glomerulosclerosis, interstitial fibrosis, tubular atrophy and arteriosclerosis is consistent with the diagnosis of hypertensive nephropathy. Global glomerulosclerosis involving more than $20 \%$ of glomeruli is predictive of worsening of renal function 6 months after nephrectomy [8].

The aim of this cross-sectional study was to evaluate the spectrum of non-neoplastic kidney lesions in tumour nephrectomy specimens with an objective of recognizing patients at risk for progressive renal disease after nephrectomy.

\section{MATERIALS \& METHODS}

This cross-sectional, retrospective study was performed at Gandhi Medical College, Secunderabad in the state of Telangana, India. The study was performed in the Departments of Pathology and Urology for a period of 18 months from January 2015 to June 2016. All tumour nephrectomy cases with adequate clinical history were included and nephrectomy cases indicated for non-neoplastic conditions were excluded from the study.

Detailed clinical history was acquired. The specimens were fixed in $10 \%$ formalin for 24 hours and then meticulously grossed. Representative bits were taken from the specimens and submitted for processing. The tissue bits were routinely processed and sections of 3-4 micron thickness were cut and stained with Haematoxylin and Eosin stains. The sections were then studied under microscopy and the results were recorded. This study was approved by the institutional Human Ethics Committee.

\section{STATISTICAL ANALYSIS}

Non-neoplastic pathology in tumour nephrectomy specimens was considered as primary outcome variable. Age, gender, type of renal tumour, renal function parameters, past and family history, any history of chronic diseases were considered as explanatory variables. The data was analysed by using Statistical Package for Social Sciences (SPSS) version 21. Appropriate graphical representation of the data was made using pie charts, bar charts and box plots.

\section{RESULTS}

Out of the 100 subjects studied, 64 (64\%) were known to have diabetes mellitus and 78 (78\%) were known hypertensives. Our results showed that among the different types of neoplasms, Clear Cell Renal Cell Carcinoma was highest (30\%) followed by Papillary RCC (18\%). Out of the 100 tumour nephrectomy specimens examined, 24 (24\%) specimens showed no significant non-neoplastic pathology. The most common non-neoplastic pathology observed was Diabetic Nephropathy (36\%) followed by Chronic Pyelonephritis (20\%). Hypertensive nephrosclerosis was noted in $12(12 \%)$ of the specimens. Out of the 64 known diabetic patients, Diabetic Nephropathy was observed in 36 specimens and of the 78 known hypertensives, hypertensive nephrosclerosis was observed in 12 specimens. 
Table-1: Descriptive analysis of Past History ( $\mathrm{N}=100)$

\begin{tabular}{|l|l|l|}
\hline Parameter & Frequency & Percentage \\
\hline Diabetes Mellitus & 64 & 64.0 \\
\hline Yes & 36 & 36.0 \\
\hline No & \multicolumn{2}{|l|}{} \\
\hline Hypertension & 78 & 78.0 \\
\hline Yes & 22 & 22.0 \\
\hline No &
\end{tabular}

Table-2: Descriptive analysis of Neoplasm $(\mathrm{N}=100)$

\begin{tabular}{|l|l|l|}
\hline Parameter & Frequency & Percentage \\
\hline Clear cell RCC & 60 & 60.0 \\
\hline Papillary RCC & 18 & 18.0 \\
\hline Renal Oncocytoma & 6 & 6.0 \\
\hline Sarcomatoid RCC & 6 & 6.0 \\
\hline Transitional cell carcinoma & 4 & 4.0 \\
\hline Nephroblastoma & 4 & 4.0 \\
\hline Chromophobe RCC & 2 & 2.0 \\
\hline
\end{tabular}

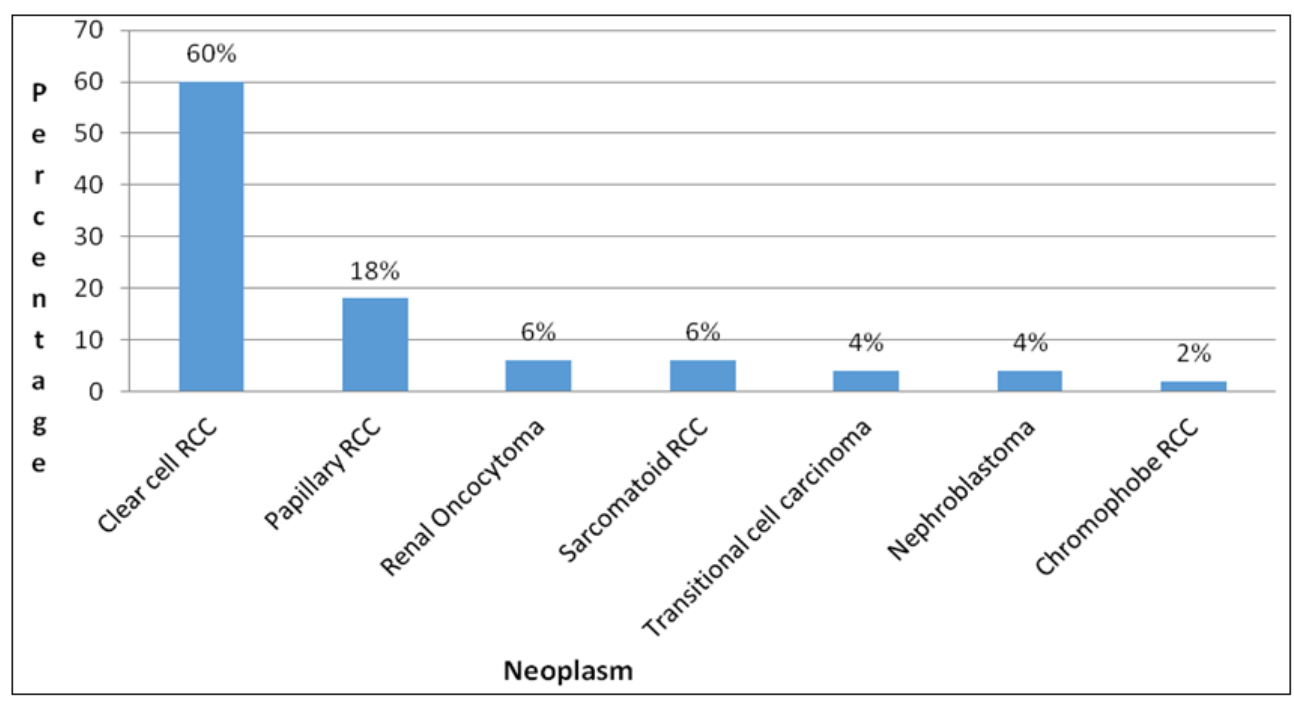

Fig-1: Bar chart of different types of neoplasm in the study population $(\mathrm{N}=100)$

Table-3: Analysis of changes in non-neoplastic renal parenchyma $(\mathrm{N}=100)$

\begin{tabular}{|l|l|l|}
\hline Non neoplastic types & Frequency & Percentage \\
\hline Normal & 24 & $24.0 \%$ \\
\hline Abnormal & 76 & $76.0 \%$ \\
\hline Diabetes Mellitus Nephropathy & 36 & 36 \\
\hline Chronic Pyelonephritis & 20 & 20 \\
\hline Hypertensive Nephrosclerosis & 12 & 12 \\
\hline Immunoglobulin A nephropathy & 4 & 4 \\
\hline Amyloidosis & 4 & 4 \\
\hline
\end{tabular}

Table-4: Analysis of non-neoplastic pathology with respect to neoplasm

\begin{tabular}{|l|l|l|l|l|l|l|}
\hline Tumor type & DM & HTN & IgA nephropathy & Amyloidosis & CPN & No change \\
\hline Clear Cell RCC & 22 & 6 & 2 & 0 & 18 & 12 \\
\hline Papillary RCC & 6 & 0 & 0 & 2 & 0 & 10 \\
\hline Chromophobe RCC & 0 & 2 & 0 & 0 & 0 & 0 \\
\hline Renal Oncocytoma & 2 & 2 & 0 & 0 & 0 & 2 \\
\hline Sarcomatoid RCC & 2 & 0 & 2 & 0 & 2 & 0 \\
\hline
\end{tabular}




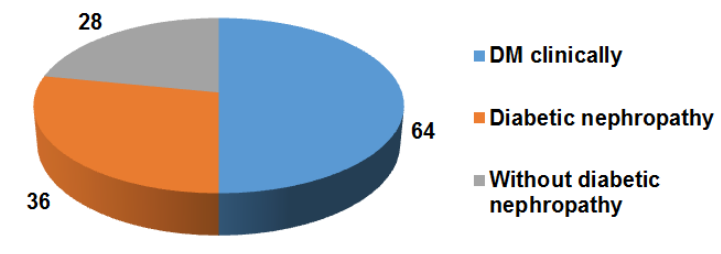

Fig-2: Pie chart showing Analysis of Diabetic Nephropathy in clinically diabetic subjects (64)
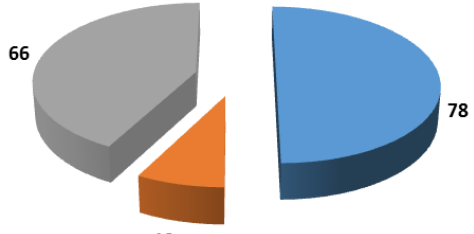

- HTN clinically

-HTN nephropathy

Without HTN

Fig-3: Pie chart showing Analysis of Hypertensive Nephropathy in clinically hypertensive subjects (78)

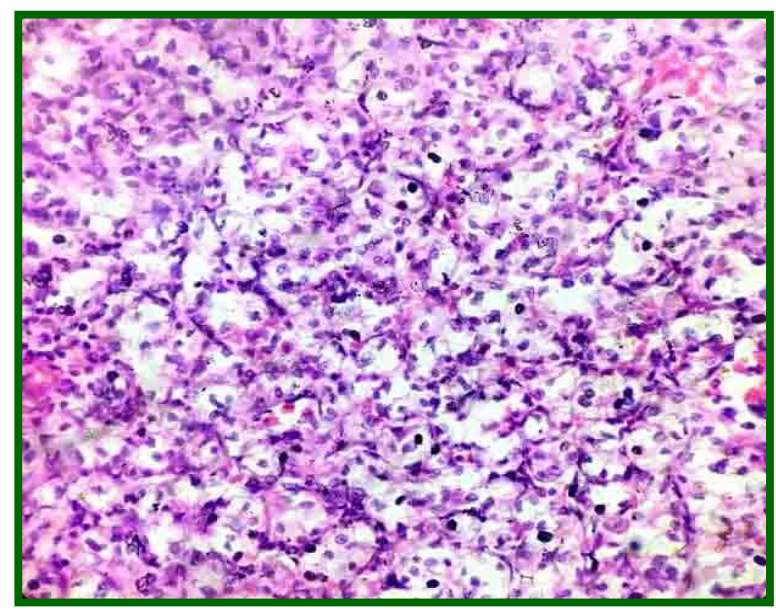

Fig-4: Microscopy of Clear Cell RCC (H\&E -40x)

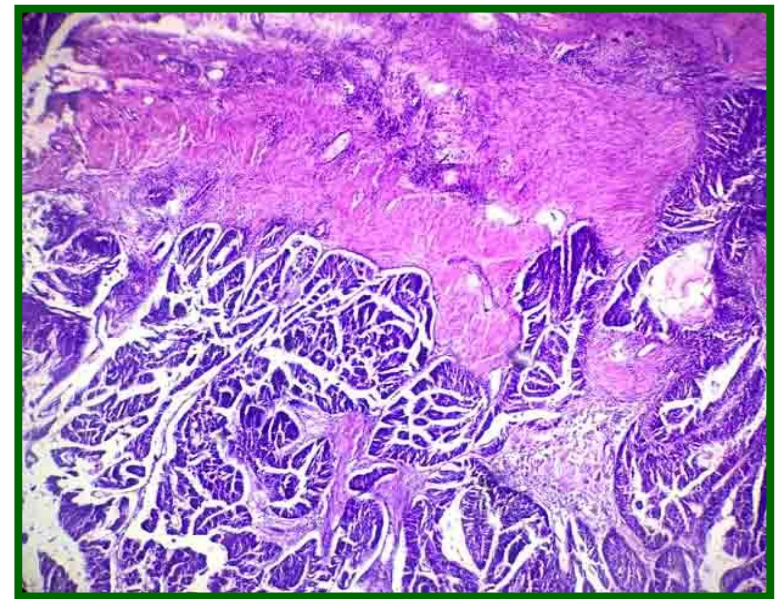

Fig-5: Microscopy of Papillary RCC (H\&E-40x)

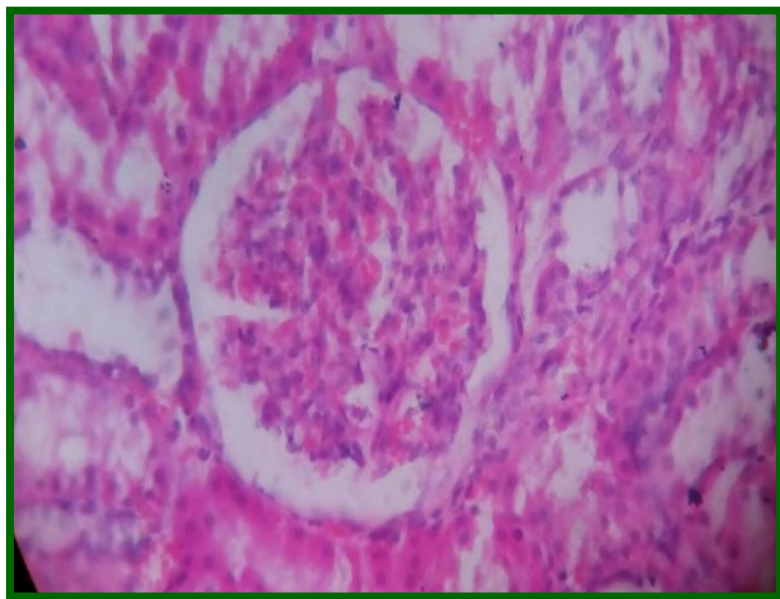

Fig-6: Histopathology of Diabetic Nephropathy showing glomerular enlargement with mild mesangial expansion $(H$ \& $\mathbf{E}-\mathbf{4 0 X})$

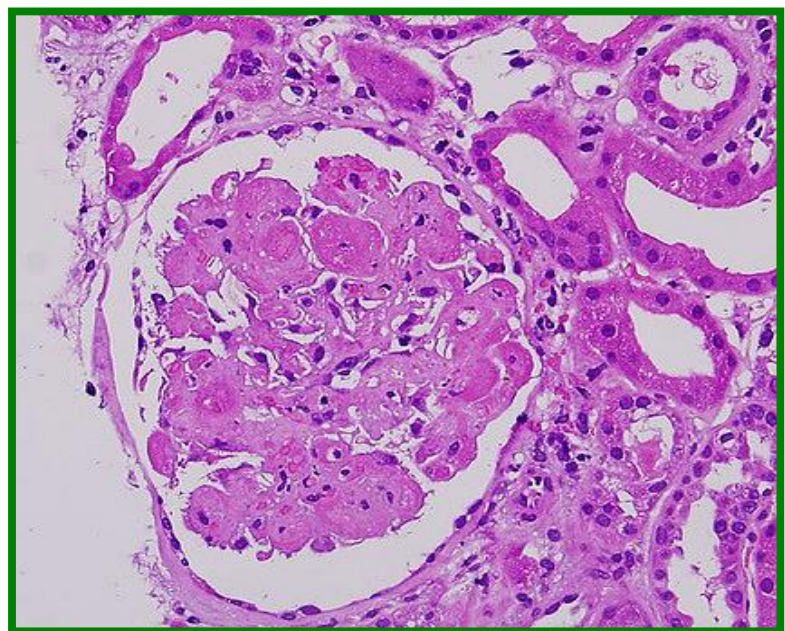

Fig-7: Histopathology of Diabetic Nephropathy showing insudative glomerular lesion FIBRIN CAP, which is the result of accumulation of plasma proteins (hyalinosis) between glomerular endothelium and the glomerular basement membrane $(\mathrm{H} \& \mathrm{E}-10 \mathrm{X})$

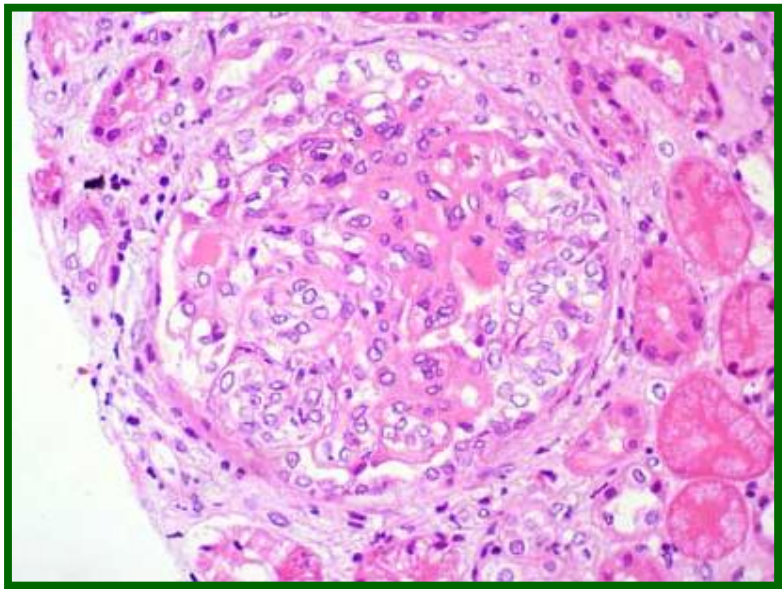

Fig-8: Histopathology of Diabetic Nephropathy showing diffuse widening of mesangium with increased matrix deposition and mild hypercellularity (H \& E Stain-10X) 


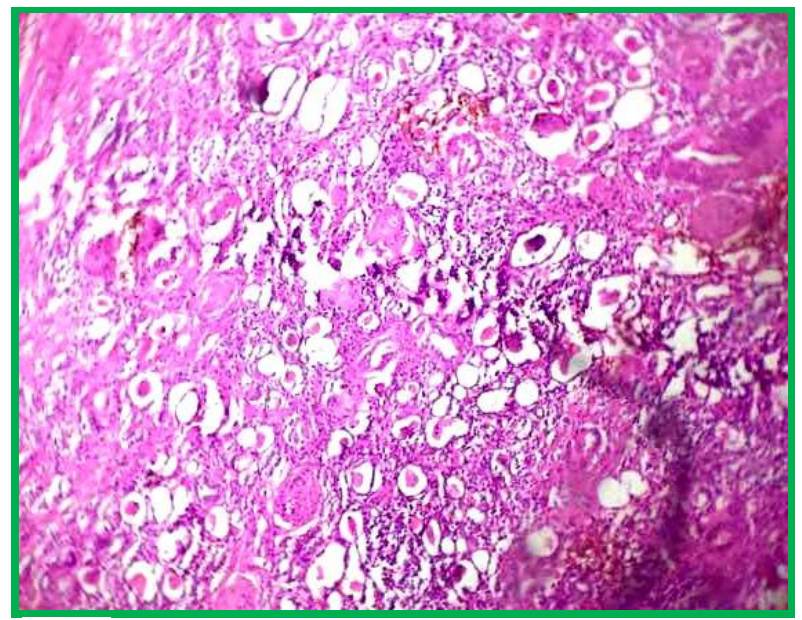

Fig-9: Histopathology of Chronic Pyelonephritis showing atrophic tubules and dense mononuclear inflammatory cell infiltrate in the interstitium $(\mathrm{H \& E}-10 \mathrm{X})$

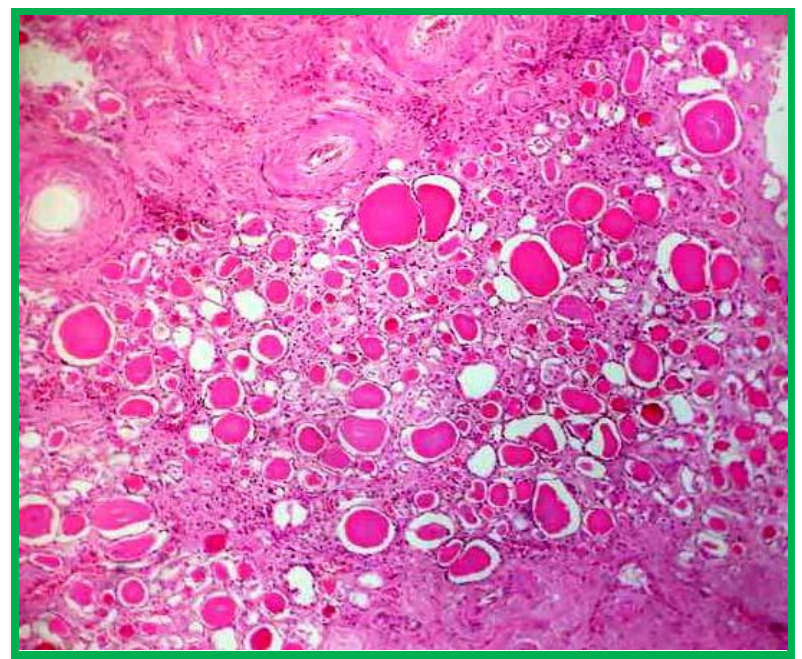

Fig-10: Histopathology of Chronic Pyelonephritis showing thyroidization (colloid in the lumen) of atrophic tubules $(\mathrm{H}$ $\& \mathbf{E}-10 X)$

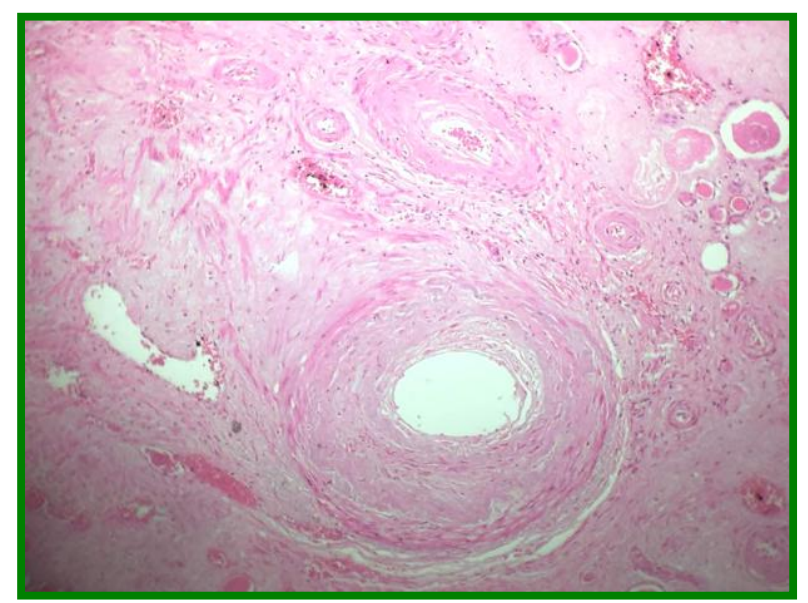

Fig-11: Histopathology of Hypertensive Nephropathy showing thickening and hyalinization of wall of small arteries and arterioles- HYALINE

ARTERIOLOSCLEROSIS, which represents plasma proteins pushed into vessel walls $(\mathrm{H} \& \mathrm{E}-10 \mathrm{X})$

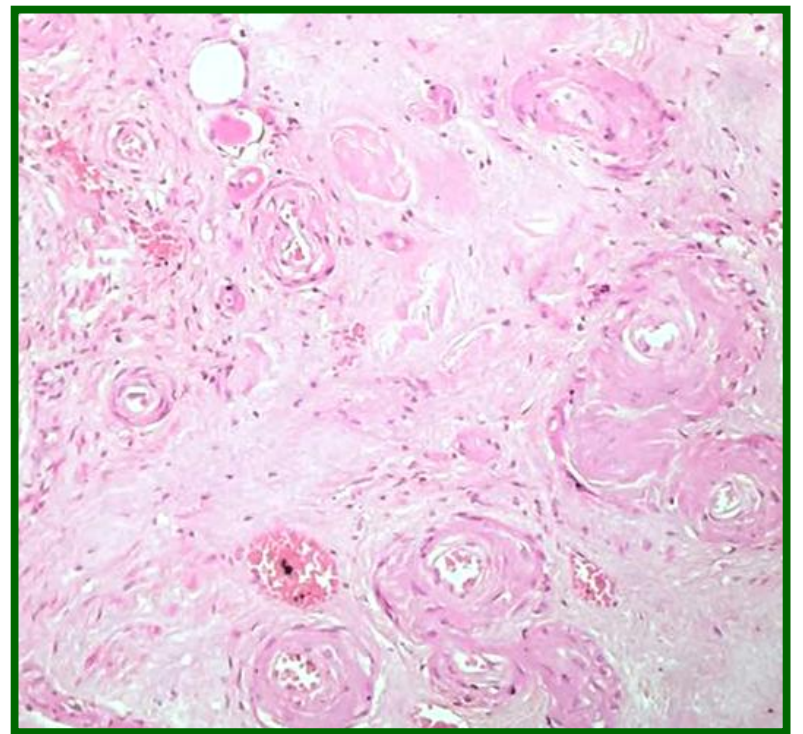

Fig-12: Histopathology of Hypertensive Nephropathy showing sclerotic glomeruli- GLOMERULOSCLEROSIS, thickening and hyalinization of wall of arteriolesHYALINE ARTERIOSCLEROSIS (H\&E10X)

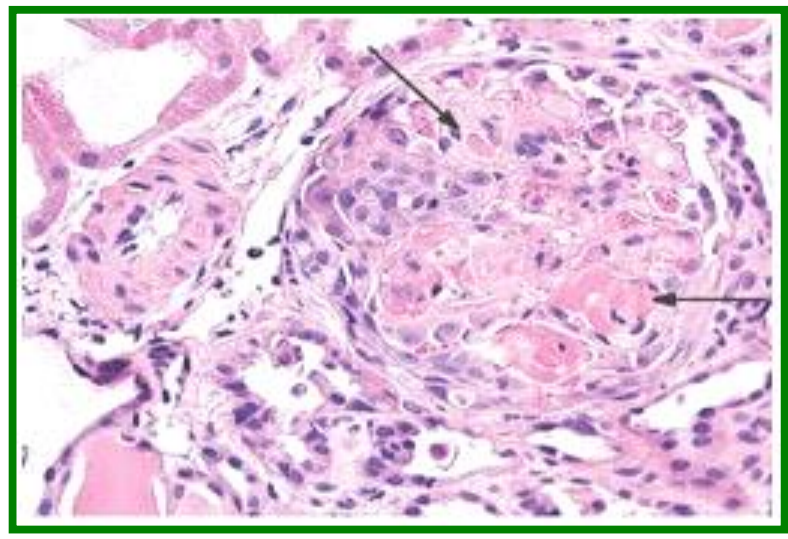

Fig-13: Histopathology of Hypertensive Nephropathy showing deposition of hyaline thrombi in the lumen of glomerular capillary loops (arrows) $(\mathrm{H} \& \mathrm{E}-10 \mathrm{X})$

\section{DISCUSSION}

Progressive renal disease is an important public health problem showing increasing prevalence throughout the world leading to significant morbidity and mortality [10]. International studies in Canada, United States of America and Europe have demonstrated an increasing incidence in Renal Cell Carcinoma (RCC) with increase in rates by $20 \%$ to $30 \%$ in recent times [11]. The concerns after nephrectomy for RCC patients involve not only the oncological outcome, but also chronic kidney disease progression because of the large amount of nephron tissue loss. The adverse renal outcomes in patients undergoing nephrectomy for RCC were determined by population based analysis. Such obstacles have also been investigated in living recipients of kidney [12, 13]. Therefore, early recognition of patients at risk for chronic kidney disease and prompt institution of treatment may be of considerable importance [14]. 
Types of neoplasm were assessed in the current study with Clear cell RCC $(60 \%)$ found to be the highest and Chromophobe RCC (2\%) was the lowest. Remaining were Papillary RCC (18\%), Renal Oncocytoma (6\%), Sarcomatoid RCC (6\%), Transitional cell carcinoma (4\%) and Nephroblastoma (4\%) respectively. Similar results were seen in a study carried out by Amin et al., [15] where Clear cell RCC was highest $(63 \%)$ followed by Papillary RCC (18.5\%) and Chromophobe RCC (5.9\%) was the lowest. Patard JJ et al., [16] also conducted a similar study and their results were also close to those obtained in the current study, where Clear cell RCC, Papillary RCC and Chromophobe RCC were $87.7 \%, 9.7 \%$ and $2.5 \%$ respectively.

Our findings of non-neoplastic pathology in tumour nephrectomy specimens corroborate well with the observations made by other researchers in earlier studies [13-19]. In our study, Diabetic Nephropathy was observed in $36 \%$ of the cases while Henriksen KJ et al., [18] reported Diabetic Nephropathy in $20 \%$ of the cases and Salvatore SP et al., [19] reported the same in $7.34 \%$ of the cases.

Out of the total 100 specimens studied, $76 \%$ showed significant non-neoplastic pathology which emphasizes the importance of medical follow up of the patient with regular laboratory investigations to assess renal function. Early institution of preventive and therapeutic management can delay progress of chronic kidney disease. This can lead to prevention of End Stage Renal Disease (ESRD) thereby improving the quality of life of nephrectomy patients.

\section{CONCLUSION}

Chronic kidney disease is a major cause of morbidity and mortality leading to significant burden on health care system and low quality of life for the patient. Given the relatively favourable 5-year survival rates for renal cell carcinomas, accurate evaluation of the non-neoplastic kidney parenchyma is imperative. The practicing surgical pathologist should be aware of the importance of both correctly classifying the renal neoplasm and the concomitant non-neoplastic kidney disease that may be present but often overlooked. Regular medical follow up and care with appropriate management of the underlying renal medical disorder is crucial in preventing or delaying onset of end stage renal disease (ESRD).

\section{REFERENCES}

1. Tavani, A., \& La, C. V. (1997). Epidemiology of renal-cell carcinoma. Journal of nephrology, 10(2), 93-106.

2. Kabaria, R., Klaassen, Z., \& Terris, M. K. (2016). Renal cell carcinoma: links and risks. International journal of nephrology and renovascular disease, $9,45-52$.
3. Mohan, V., Sandeep, S., Deepa, R., Shah, B., \& Varghese, C. (2007). Epidemiology of type 2 diabetes: Indian scenario. The Indian journal of medical research, 125(3), 217-30.

4. Lindblad, P., Chow, W. H., Chan, J., Bergström, A., Wolk, A., Gridley, G., ... \& Adami, H. O. (1999). The role of diabetes mellitus in the aetiology of renal cell cancer. Diabetologia, 42(1), 107-112.

5. Zucchetto, A., Dal Maso, L., Tavani, A., Montella, M., Ramazzotti, V., Talamini, R., ... \& La Vecchia, C. (2007). History of treated hypertension and diabetes mellitus and risk of renal cell cancer. Annals of Oncology, 18(3), 596-600.

6. Hepps, D., \& Chernoff, A. (2006, September). Risk of renal insufficiency in African-Americans after radical nephrectomy for kidney cancer. In Urologic Oncology: Seminars and Original Investigations (Vol. 24, No. 5, pp. 391-395). Elsevier.

7. Huang, W. C., Levey, A. S., Serio, A. M., Snyder, M., Vickers, A. J., Raj, G. V., ... \& Russo, P. (2006). Chronic kidney disease after nephrectomy in patients with renal cortical tumours: a retrospective cohort study. The lancet oncology, 7(9), 735-740.

8. Bijol, V., Mendez, G. P., Hurwitz, S., Rennke, H. G., \& Nosé, V. (2006). Evaluation of the nonneoplastic pathology in tumor nephrectomy specimens: predicting the risk of progressive renal failure. The American journal of surgical pathology, 30(5), 575-584.

9. Henriksen, K. J., Meehan, S. M., \& Chang, A. (2007). Non-neoplastic renal diseases are often unrecognized in adult tumor nephrectomy specimens: a review of 246 cases. The American journal of surgical pathology, 31(11), 1703-1708.

10. Shrivastava, U., Misra, A., Mohan, V., Unnikrishnan, R., \& Bachani, D. (2017). Obesity, diabetes and cardiovascular diseases in India: public health challenges. Current diabetes reviews, 13(1), 65-80.

11. Williamson, T. J., Pearson, J. R., Ischia, J., Bolton, D. M., \& Lawrentschuk, N. (2016). Guideline of guidelines: follow- up after nephrectomy for renal cell carcinoma. BJU international, 117(4), 555-562.

12. Sejima, T., Honda, M., \& Takenaka, A. (2015). Renal parenchymal histopathology predicts lifethreatening chronic kidney disease as a result of radical nephrectomy. International Journal of Urology, 22(1), 14-21.

13. Sejima, T., Yumioka, T., Yamaguchi, N., Iwamoto, H., Masago, T., Morizane, S., ... \& Takenaka, A. (2016). Characterization of mild and severe post-radical nephrectomy renal functional deterioration utilizing histopathological evaluation of non-neoplastic 
nephrectomized renal parenchyma. International journal of clinical oncology, 21(3), 588-594.

14. Wee, J. W., Kang, H. R., Kwon, S. H., Jeon, J. S., Han, D. C., Jin, S. Y., ... \& Noh, H. (2016). Clinical value of pathologic examination of nonneoplastic kidney in patients with upper urinary tract malignancies. The Korean Journal of Internal Medicine, 31(4), 739-749.

15. Amin, M. B., Amin, M. B., Tamboli, P., Javidan, J., Stricker, H., Venturina, M. D. P., ... \& Menon, M. (2002). Prognostic impact of histologic subtyping of adult renal epithelial neoplasms: an experience of 405 cases. The American journal of surgical pathology, 26(3), 281-291.

16. Patard, J. J., Leray, E., Rioux-Leclercq, N., Cindolo, L., Ficarra, V., Zisman, A., ... \& Pantuck, A. J. (2005). Prognostic value of histologic subtypes in renal cell carcinoma: a multicenter experience. Journal of Clinical Oncology, 23(12), 2763-2771.

17. Sarsık, B., Şimşir, A., Yılmaz, M., Yörükoğlu, K., \& Şen, S. (2013). Spectrum of nontumoral renal pathologies in tumor nephrectomies: nontumoral renal parenchyma changes. Annals of diagnostic pathology, 17(2), 176-182.

18. Henriksen, K. J., Meehan, S. M., \& Chang, A. (2009). Nonneoplastic kidney diseases in adult tumor nephrectomy and nephroureterectomy specimens: common, harmful, yet underappreciated. Archives of pathology \& laboratory medicine, 133(7), 1012-1025.

19. Salvatore, S. P., Cha, E. K., Rosoff, J. S., \& Seshan, S. V. (2013). Nonneoplastic renal cortical scarring at tumor nephrectomy predicts decline in kidney function. Archives of Pathology \& Laboratory Medicine, 137(4), 531540 . 